\title{
Differentiating between direct and indirect exposure to exhaled particles in indoor environments with mechanical ventilation systems
}

\author{
Chun Chen ${ }^{1,2,3, *}$, and Ruoyu You, \\ ${ }^{1}$ Department of Mechanical and Automation Engineering, The Chinese University of Hong Kong, Shatin, N.T. 999077, Hong Kong \\ SAR, China \\ ${ }^{2}$ Shun Hing Institute of Advanced Engineering, The Chinese University of Hong Kong, Shatin, N.T. 999077, Hong Kong SAR, China \\ ${ }^{3}$ Shenzhen Research Institute, The Chinese University of Hong Kong, Shenzhen 518057, China \\ ${ }^{4}$ Department of Building Services Engineering, The Hong Kong Polytechnic University, Kowloon, 999077, Hong Kong SAR, China
}

\begin{abstract}
Exhaled contaminants transported in the air can result in the transmission of many airborne infectious diseases in indoor environments. When the exhaled air from the infected person directly enters the breathing zone of another person, direct exposure occurs. When the exhaled contaminants disperse in the room and then are inhaled by another person, indirect exposure occurs. This investigation developed a method for differentiating the direct and indirect exposure to exhaled contaminants in indoor environments with mechanical ventilation. A literature review was conducted to collect experimental data for 191 personto-person contaminant transport cases. With the analysis of the database, a mathematical method was developed to differentiate direct and indirect exposure in rooms with mixing and displacement ventilation systems. The proposed method correctly differentiated direct and indirect exposure for 120 out of the 133 mixing ventilation cases and 47 out of the 58 displacement ventilation cases. It can be used at the early design stage to quickly assess whether there will be direct exposure to exhaled contaminants in a room with mechanical ventilation systems.
\end{abstract}

\section{Introduction}

The airborne transmission of infectious diseases in indoor environments has been become a major public health concern worldwide [1]. An infected person can exhale particles carrying infectious viruses which can be transported to the breathing zone of other persons via the air and cause cross infection. Many outbreaks of airborne infectious diseases have occurred indoors through this transmission route. Therefore, it is crucial to investigate the indoor exposure to exhaled contaminants in mechanically ventilated rooms to improve air distribution design and reduce the risk of infection.

In general, there are two modes of personal exposure to exhaled contaminants: direct exposure and indirect exposure [2-4]. Direct exposure occurs when the exhaled jet carrying contaminants from the source person directly enters the breathing zone of the target person. Thus, direct exposure is determined primarily by the impact scope of the exhaled air [5]. In contrast, indirect exposure occurs when contaminants disperse in the room and are inhaled by the target person. Therefore, indirect exposure is determined primarily by the ventilation in the room.

At the early stage of ventilation design, it may be desirable to have a simple method to quickly assess personal exposure to exhaled contaminants. If the assessment shows that direct exposure may occur, we should consider separating individuals by altering the design for the interior layout, for example by increasing the distance between seats. If the assessment shows that only indirect exposure will occur, we should focus on how to achieve a healthier indoor environment by improving the design of the air distribution system. Therefore, to better support decision making at an early design stage, this study aimed to develop a simple method for differentiating direct and indirect exposure to exhaled contaminants in mechanically ventilated rooms.

\section{Review of experimental data}

We first collected the experimental data of personal exposure to exhaled contaminants from 10 scientific papers [6-15] to create a database. Data for 191 cases of personal exposure to exhaled contaminants were extracted from the figures or tables in the literature. When collecting the data, we focused on two major types of ventilation mode: mixing ventilation and displacement ventilation. Downward ventilation was categorized as mixing ventilation based on the similar performance in controlling person-to-person contaminant transport in the literature. Other ventilation modes, such as protective ventilation and personalized ventilation were not

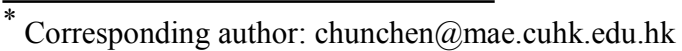


included. There were 133 mixing ventilation cases and 58 displacement ventilation cases. The tested ventilation rate ranged from 0.71 to $12 \mathrm{ACH}$ (air change per hour). The studied person-to-person distance ranged from 0.35 to $3.0 \mathrm{~m}$. Personal exposure to exhaled contaminants was normalized by the concentration at the exhaust of the room as follows:

$$
\overline{\mathrm{C}}=\frac{\mathrm{C}_{\text {exp }}}{\mathrm{C}_{\mathrm{R}}}
$$

where $\mathrm{C}_{\exp }\left(\# / \mathrm{m}^{3}\right)$ is the exhaled contaminant concentration measured in the breathing zone of the target person, and $C_{R}\left(\# / \mathrm{m}^{3}\right)$ is the exhaled contaminant concentration measured at the exhaust. In a well-mixed condition, the normalized exposure is equal to 1.0. Among the 191 cases, the normalized exposure varied significantly from 0.01 to 13.0 , deviations from the wellmixed condition of more than one order of magnitude.

To differentiate the direct-exposure cases and indirect-exposure-only cases, a cutoff value of normalized exposure should be defined. If the room air is well-mixed in all of the cases, the cutoff value of normalized exposure can be set at 1.0. However, it is difficult to achieve the well-mixed condition in actual engineering applications. There must be a certain degree of non-uniform distribution in the room. Therefore, this study set the cutoff normalized exposure at 1.2 for mixing ventilation, i.e. $20 \%$ higher than the theoretical value. That is to say, if the normalized exposure is lower than or equal to 1.2 , this indicates no direct exposure, only indirect exposure to the background concentration in the room. Using this definition, there were 28 directexposure cases and 105 indirect-exposure-only cases for mixing ventilation in the database. Using the same definition, there were 30 direct-exposure cases and 28 indirect-exposure-only cases for displacement ventilation in the database.

\section{Development of the methods}

\subsection{Mixing ventilation}

Figure 1 shows the typical scenarios of person-toperson contaminant transport in a mixing ventilated room. The source person exhales air with contaminants through breathing, coughing, or sneezing. The breathing zone of the target person is defined as a cube with a volume of $0.027 \mathrm{~m}^{3}$ in front of his/her mouth [4]. As illustrated in Figure 1(a), when the breathing zone of the target person is within the impact scope of the exhaled air, serious direct exposure to the exhaled contaminants may occur. In contrast, when the breathing zone of the target person is far away from the impact scope of the exhaled air, only indirect exposure will occur, as shown in Figure 1(b). Another common scenario, as shown in Figure 1(c), is the source and target facing in the same direction, such as people in a concert audience or students seated in a classroom. In such cases, even though the target person is close to the exhaled air, direct exposure may be avoided because the pathway to the breathing zone is blocked by the head. Figure 1(d) shows another scenario related to the thermal plume generated by the target person, which has been proven to be important in the near-body airflow field and contaminant transport [4]. When the exhaled air penetrates the lower zone of the thermal plume boundary layer, the contaminants may move upward with the vertical airflow driven by the thermal plume and enter the breathing zone. In this case, direct exposure may occur. These four scenarios were included for analysis.
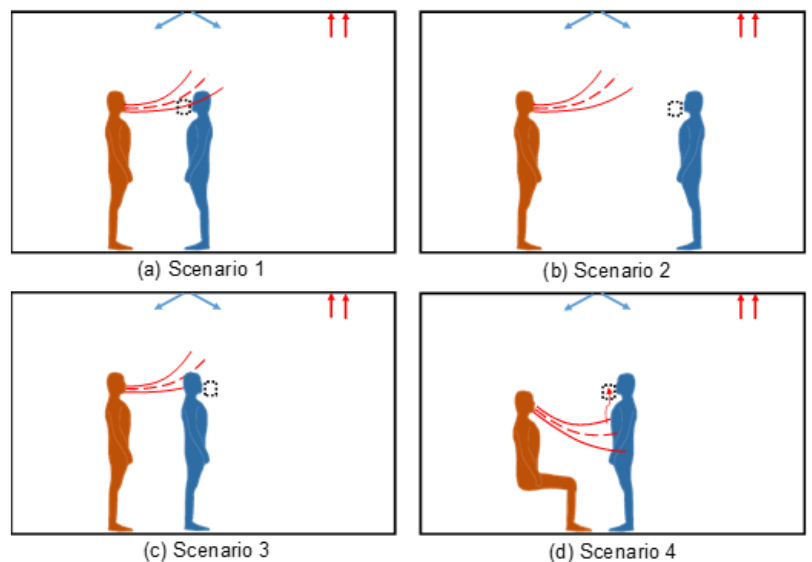

Fig. 1. Person-to-person contaminant transport in a mixing ventilated room: (a) direct exposure: the breathing zone of the target person is within the impact scope of exhaled air, (b) indirect exposure: the breathing zone of the target person is far away from the impact scope of exhaled air, (c) indirect exposure: the pathway of exhaled air to the breathing zone is blocked by the head of the target person, and (d) direct exposure: exhaled air penetrates the thermal plume boundary layer generated by the target person.

To determine the impact scope, it is crucial to understand the nature of the exhaled air. Exhaled air is usually at a relatively high temperature compared with the room air temperature. Therefore, the exhaled jet is non-isothermal with a curved trajectory as shown in Figure 2. After leaving the mouth or nose, the exhaled jet mixes with the room air and grows thicker. A free round jet consists of an initial section and a main section. In the potential core of the initial section, the centerline velocity of the jet is equal to the initial velocity at the mouth/nose and the radial velocity component is zero. The air velocity distribution in the mixing layer of the initial region is similar to that in the main section, but the maximum velocity is from the centerline to the edge of the potential core. In the main section, the centerline velocity decreases with the increase in the distance from the mouth/nose.

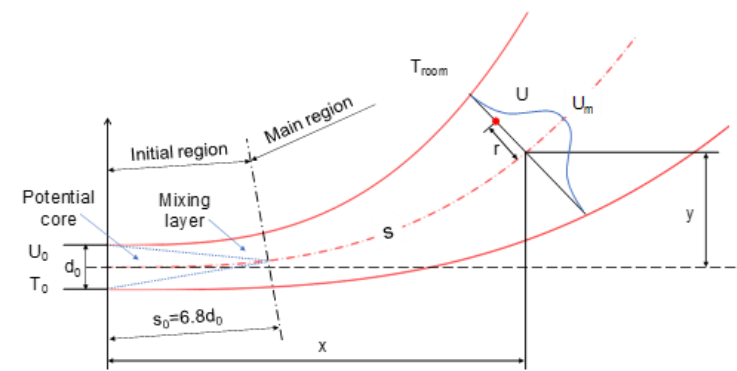


Fig. 2. Illustration of a non-isothermal round jet (modified from Figure 2 of [16].

For a non-isothermal round jet, the trajectory equation of the curved centerline can be determined by the following equation:

$$
y=0.0354 \frac{\mathrm{Ar}_{0}}{\mathrm{~A}_{0}} \sqrt{\frac{\mathrm{T}_{0}}{\mathrm{~T}_{\mathrm{r}}}} \cdot \mathrm{x}^{3} \equiv \xi \cdot \mathrm{x}^{3}
$$

where $A_{0}\left(\mathrm{~m}^{2}\right)$ is the area of the mouth/nose opening, $T_{0}$ $(\mathrm{K})$ is the temperature of the exhaled air, $\mathrm{T}_{\mathrm{r}}(\mathrm{K})$ is the room air temperature, and $\mathrm{Ar}_{0}$ is the Archimedes number, which can be calculated by

$$
\mathrm{Ar}_{0}=\frac{\mathrm{g} \sqrt{\mathrm{A}_{0}} \alpha\left(\mathrm{T}_{0}-\mathrm{T}_{\mathrm{r}}\right)}{\mathrm{U}_{0}^{2}}
$$

where $g\left(\mathrm{~m} / \mathrm{s}^{2}\right)$ is the gravitational acceleration, $\alpha(1 / \mathrm{K})$ is the thermal expansion coefficient of air, and $U_{0}(\mathrm{~m} / \mathrm{s})$ is the initial velocity at the mouth/nose. Note that, when the exhaled air direction is not horizontal, the coordinate system shown in Figure 2 should be altered accordingly. With the curved centerline trajectory of the exhaled air, the relative coordinates of the breathing zone center point, s and r, can be determined. Line_1 is a tangent line to the curved trajectory of exhaled air centerline at the cross point $\left(\mathrm{x}_{\mathrm{c}}, \mathrm{y}_{\mathrm{c}}\right)$. Line_2 is perpendicular to Line 1 and passes through both the cross point $\left(\mathrm{x}_{\mathrm{c}}, \mathrm{y}_{\mathrm{c}}\right)$ and the breathing zone center point $\left(\mathrm{x}_{\mathrm{b}}, \mathrm{y}_{\mathrm{b}}\right)$. After derivation, the relative coordinates of the breathing zone center point to the exhaled jet centerline, $\mathrm{s}$ and $\mathrm{r}$, can be calculated by

$$
\begin{aligned}
& \mathrm{s}=\int_{0}^{\mathrm{x}_{\mathrm{c}}} \sqrt{(\mathrm{dx})^{2}+\left[\xi(\mathrm{x}+\mathrm{dx})^{3}-\xi \mathrm{x}^{3}\right]^{2}} \mathrm{dx} \\
& \mathrm{r}=\sqrt{\left(\mathrm{y}_{\mathrm{c}}-\mathrm{y}_{\mathrm{b}}\right)^{2}+\left(\mathrm{x}_{\mathrm{c}}-\mathrm{x}_{\mathrm{b}}\right)^{2}}
\end{aligned}
$$

With the relative coordinates of the breathing zone center point, $s$ and $r$, the local air velocity at this point can be calculated using jet theory. In this case, we used the jet expressions from [16]. The centerline velocity can be calculated by

$$
\mathrm{U}_{\mathrm{m}}=\frac{6.8 \mathrm{U}_{0}}{\overline{\mathrm{s}}}
$$

where $U_{m}(\mathrm{~m} / \mathrm{s})$ is the centerline velocity, and $U_{0}(\mathrm{~m} / \mathrm{s})$ is the initial velocity at the mouth/nose, and s (unitless) is the dimensionless centerline distance, which is defined as

$$
\overline{\mathrm{s}}=\frac{\mathrm{s}}{\mathrm{d}_{0}}
$$

where $\mathrm{d}_{0}$ is the diameter of the mouth/nose opening. The mean axial velocity component, $\mathrm{u}_{\mathrm{s}}(\mathrm{m} / \mathrm{s})$, and mean radial velocity component, $u_{\mathrm{r}}(\mathrm{m} / \mathrm{s})$, can be calculated by

$$
\mathrm{u}_{\mathrm{s}}=\mathrm{U}_{\mathrm{m}} \operatorname{sech}^{2}(\sigma \eta)
$$

$$
u_{r}=U_{m} \frac{a \eta\left(1+\eta^{2}-(1+b) \sqrt{1+\eta^{2}}\right)}{\left(1+\eta^{2}\right)\left(1-(1+b) \sqrt{1+\eta^{2}}\right)^{2}}
$$

where $\sigma$ is equal to 10.4 , a is equal to 0.0046 , $\mathrm{b}$ is equal to 0.0075 , and $\eta$ is defined as

$$
\eta=\frac{r}{s}
$$

where $r(m)$ is the distance from the target location to the centerline. Therefore, the velocity magnitude at a location in the jet with the coordinates of $\mathrm{s}$ and $\mathrm{r}, \mathrm{U}$ $(\mathrm{m} / \mathrm{s})$, is equal to

$$
\mathrm{U}=\sqrt{\mathrm{u}_{\mathrm{s}}^{2}+\mathrm{u}_{\mathrm{r}}^{2}}
$$

Based on similarity theory, the contaminant concentration at a given location in the jet is correlated to the local air velocity. Therefore, we used the local air velocity (U) at the center of the target person's breathing zone calculated by the model above as an indicator to differentiate the direct and indirect exposure to exhaled contaminants. When the local air velocity is significantly higher than a certain threshold, $\mathrm{U}^{*}$, (to be determined later), the local contaminant concentration in the breathing zone also tends to be significantly higher than the background concentration in the room. Note that here the threshold velocity is a hypothetical velocity calculated for the exhaled jet, which did not consider the exhaled jet by the infected person. In such cases, the breathing zone of the target person is within the impact scope of the exhaled air, so that direct exposure may occur (Scenario 1). In contrast, if the local air velocity is lower than the threshold, the local contaminant concentration in the breathing zone should be similar to the background concentration in the room. In such cases, it is considered that there is no direct exposure but only indirect exposure to the background concentration in the room (Scenario 2).

Two special scenarios, Scenarios 3 and 4 (shown in Figure 1) should be further considered. When the pathway from the exhaled air to the breathing zone is blocked by the head of the target person, (e.g. two persons facing in the same direction, one behind the other), the exposure is considered to be indirect only (Scenario 3). To determine whether the thermal plume generated by the target person will result in direct exposure, more calculations are needed, as illustrated in Figure 3. In the coordinate system shown in Figure 3, the function of the exhaled air centerline trajectory can still be described by eq. (3). Line_3 is a line along the body of the target person across the breathing zone center point. This line can be roughly regarded as the pathway of the upward thermal plume. Line_3 is perpendicular to Line_4; thus, the slop of Line_3 can be calculated by

$$
\beta_{3}=-\frac{1}{\beta_{4}}=-\frac{1}{\tan \theta}
$$

where $\theta$ is the angle between the $\mathrm{x}$-axis and Line_ 4 shown in Figure 3. Therefore, the function of Line_3 is 


$$
y=-\frac{1}{\tan \theta} x+c
$$

where $\mathrm{c}$ is a constant which can be determined by

$$
\mathrm{c}=\mathrm{y}_{\mathrm{b}}+\frac{1}{\tan \theta} \mathrm{x}_{\mathrm{b}}
$$

because the breathing zone center point $\left(\mathrm{x}_{\mathrm{b}}, \mathrm{y}_{\mathrm{b}}\right)$ is also on Line 3. Thus, the coordinates of the cross point $\left(x_{t}, y_{t}\right)$ can be obtained. If the cross point is below the breathing zone center point (i.e., $\mathrm{y}_{\mathrm{t}} \leqslant \mathrm{y}_{\mathrm{b}}$ ), the cross point is considered to be within the boundary layer of the thermal plume generated by the target person. The next step is to calculate the local air velocity at the cross point, $U_{t}$. If this local air velocity is greater than the threshold local air velocity, the exhaled contaminant concentration at the cross point is significantly higher than the background concentration. That means a considerable amount of exhaled contaminants enter the boundary layer of the thermal plume. Here, we assume that these contaminants will move upward with the thermal plume to the breathing zone of the target person (Scenario 4).

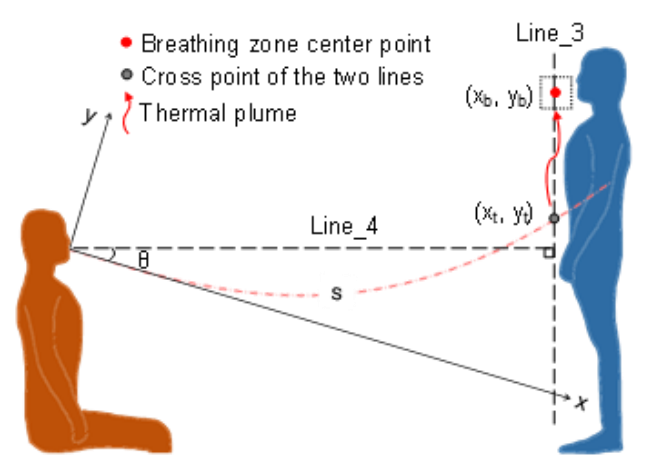

Fig. 3. Determining the coordinates of the cross point $\left(x_{t}, y_{t}\right)$ and its relative position to the center point of the breathing zone.

With this differentiation strategy discussed above, the remaining problem is how to define the threshold local air velocity, $\mathrm{U}^{*}$, to determine the impact scope of the exhaled air. We used the experimental data from the literature to determine the threshold local air velocity by sensitivity analysis. Note that this study set the cutoff normalized exposure at 1.2 to differentiate the directexposure cases and indirect-exposure-only cases for mixing ventilation as defined in the last paragraph of section 2.1. When the threshold local air velocity was $0.05 \mathrm{~m} / \mathrm{s}$, the error of the proposed method was the lowest, at $9.8 \%$. Thus, the proposed method could correctly differentiate the direct $\left(\mathrm{C}_{\mathrm{exp}} / \mathrm{C}_{\mathrm{R}}>1.2\right)$ and indirect $\left(\mathrm{C}_{\mathrm{exp}} / \mathrm{C}_{\mathrm{R}} \leqslant 1.2\right)$ exposure for 120 out of the 133 mixing ventilation cases. Therefore, the threshold local air velocity was set at $0.05 \mathrm{~m} / \mathrm{s}$ in the method for differentiating the direct and indirect exposure to exhaled contaminants in mixing ventilated rooms.

The proposed method was used to differentiate the direct and indirect exposure to exhaled contaminants for the 133 mixing ventilation cases. Figure 4 shows the distribution of the measured normalized exposure for the predicted direct-exposure cases and indirect-exposureonly cases. From the experimental data, there were 28 direct-exposure cases and 105 indirect-exposure-only cases for mixing ventilation. The proposed method correctly identified 22 direct-exposure cases and 98 indirect-exposure-only cases. In general, with a threshold local air velocity of $0.05 \mathrm{~m} / \mathrm{s}$ the proposed method can reasonably differentiate direct and indirect exposure to exhaled air in mixing ventilation conditions. The median value for the predicted indirect-exposure-only cases was 0.96 , which is close to the theoretical value of 1.0 . In contrast, the median value for the predicted directexposure cases was 2.45 , which is significantly higher than 1.0 , owing to the direct exposure to exhaled contaminants.

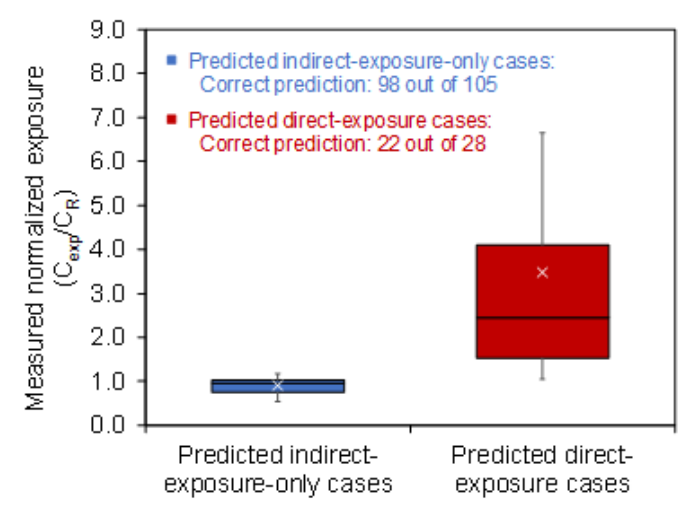

Fig. 4. Measured normalized exposure for the predicted indirect-exposure-only and direct-exposure cases in mixing ventilation (the $10^{\text {th }}, 25^{\text {th }}$, median, mean, $75^{\text {th }}$, and $90^{\text {th }}$ percentile values are shown).

\subsection{Displacement ventilation}

Figure 5 shows the typical scenarios of person-toperson contaminant transport in a displacement ventilated room. The four scenarios are similar to that shown in Figure 1, but there are two major differences. First, if the target person is far away from the impact scope of exhaled air, the clean air supplied from the displacement ventilation diffuser may directly enter the breathing zone so that exposure can be reduced. Therefore, in general, the indirect exposure under displacement ventilation is lower than that under mixing ventilation. Second, the exhaled air may be locked in the thermal stratification layer created by the displacement ventilation. In such cases, the exhaled air tends to move more horizontally and have an impact over a greater distance. To consider the lock-up phenomenon in the thermal stratification layer but still keep the method as simple as possible, we assumed that the exhaled air moves horizontally even though the Archimedes number is not zero. Note that this assumption tends to result in an over-estimation of direct exposure, because the actual trajectory of the exhaled air is still curved to some extent at the beginning and the lock-up height can be higher than the starting point of the exhaled air. Therefore, to compensate for this effect, the threshold local air velocity was determined separately for displacement 
ventilation. In theory, the threshold local air velocity for displacement ventilation should be greater than that for mixing ventilation.
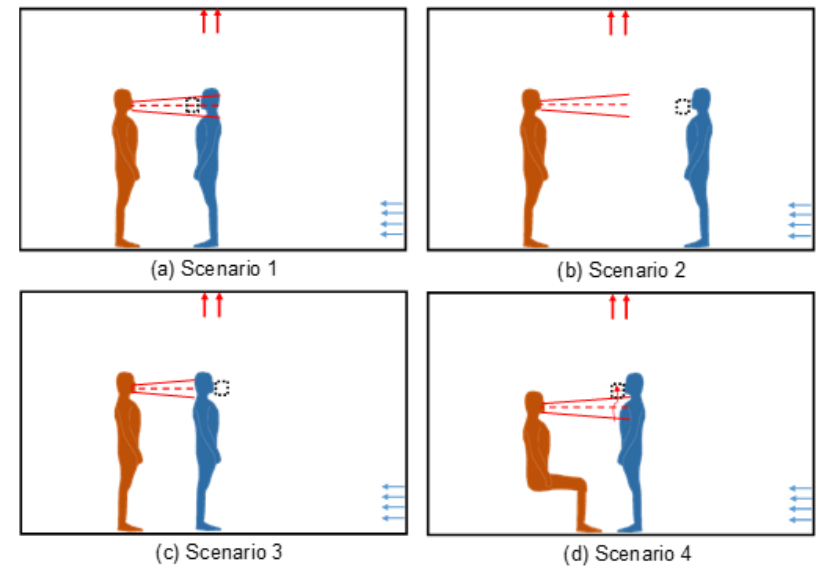

Fig. 5. Schematic of person-to-person contaminant transport in a displacement ventilated room: (a) direct exposure: the breathing zone of the target person is within the impact scope of exhaled air, (b) indirect exposure: the target person is far away from the impact scope of exhaled air, (c) indirect exposure: the pathway of exhaled air to the breathing zone is blocked by the head of the target person, and (d) direct exposure: exhaled air penetrates the thermal plume boundary layer generated by the target person.

We used the collected experimental data from the literature to determine the threshold local air velocity for displacement ventilation. Note that this study set the cutoff normalized exposure at 1.2 to differentiate the direct-exposure cases and indirect-exposure-only cases for displacement ventilation as defined in the last paragraph of section 2.1. When the threshold local air velocity was $0.07 \mathrm{~m} / \mathrm{s}$, the error of the proposed method was $19.0 \%$, the lowest among all of the tested local air velocities. This means that the proposed method could correctly differentiate direct $\left(\mathrm{C}_{\exp } / \mathrm{C}_{\mathrm{R}}>1.2\right)$ and indirect $\left(\mathrm{C}_{\mathrm{exp}} / \mathrm{C}_{\mathrm{R}} \leqslant 1.2\right)$ exposure for 47 out of the 58 displacement ventilation cases. Therefore, the threshold local air velocity was set at $0.07 \mathrm{~m} / \mathrm{s}$ in the method for differentiating the direct and indirect exposure to exhaled contaminants in displacement ventilated rooms. As predicted, the threshold local air velocity for displacement ventilation is higher than that for mixing ventilation, so that the over-estimation of direct exposure due to the assumption of non-curved exhaled air trajectory can be compensated.

The proposed method was applied to differentiate direct and indirect exposure to exhaled contaminants for the 58 displacement ventilation cases. Figure 6 shows the distribution of the measured normalized exposure for the predicted direct-exposure cases and indirectexposure-only cases. The experimental database contained 30 direct-exposure cases and 28 indirectexposure-only cases for displacement ventilation. The proposed method correctly identified 37 direct-exposure cases and 21 indirect-exposure-only cases. In general, with a threshold local air velocity of $0.07 \mathrm{~m} / \mathrm{s}$ the proposed method can reasonably differentiate direct and indirect exposure to exhaled air for displacement ventilation. The median value for the predicted directexposure cases was 1.92 , which is significantly higher than 1.0, owing to the direct exposure to exhaled contaminants. In contrast, the median value for the predicted indirect-exposure-only cases was 0.60 , which is lower than that for mixing ventilation. That is because when the target person is not impacted directly by the exhaled air, the exposure is reduced by the clean air supplied from the lower zone of the room directly entering the breathing zone. Furthermore, the variation of the normalized exposure for displacement ventilation was greater than that for mixing ventilation. For example, the range between the $25^{\text {th }}$ and $75^{\text {th }}$ percentile values for displacement ventilation was from 0.17 to 0.76. This indicates that, with an appropriate design, displacement ventilation has a better chance of achieving excellent performance in reducing indirect exposure to exhaled contaminants.

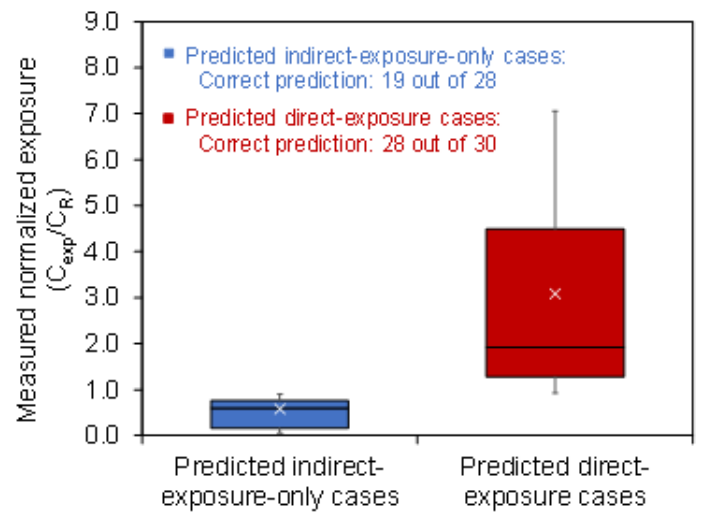

Fig. 6. The distribution of measured normalized exposure for the predicted indirect-exposure-only cases and direct-exposure cases for displacement ventilation (the $10^{\text {th }}, 25^{\text {th }}$, median, mean, $75^{\text {th }}$, and $90^{\text {th }}$ percentile values are shown).

\section{Discussion}

To keep the proposed method as simple as possible for the early stage of design, the lock-up phenomenon in the displacement ventilation cases was largely simplified in this study. The exhaled air was assumed to move horizontally even though the jet might be locked up at a greater height in reality. To compensate the potential over-estimation of direct exposure due to this assumption, the threshold local air velocity was set greater than that for mixing ventilation based on the experimental database. Furthermore, the proposed method is for quickly differentiating the direct and indirect exposure to exhaled contaminants in mechanically ventilated spaces. However, it is not for predicting the exposure levels. In general, it is difficult to accurately predict the direct exposures at the stage of design, because the information of many individual parameters is unavailable.

\section{Conclusions}


This investigation developed a simple method for differentiating direct and indirect exposure to exhaled contaminants in mechanically ventilated rooms. First, a database was formed by collecting experimental data from the literature. Then, the data were analyzed to capture the main influencing factors. Finally, a method for differentiating direct and indirect exposure was developed for both mixing and displacement ventilation. Within the scope of this research, the following conclusions can be drawn:

(1) Direct exposure to exhaled contaminants is determined primarily by the impact scope of the exhaled air.

(2) Indirect exposure to exhaled contaminants is determined primarily by the ventilation mode and ventilation rate.

(3) The proposed method can reasonably differentiate direct and indirect exposure to exhaled contaminants in both mixing and displacement ventilated rooms.

\section{Acknowledgement}

This work was partially supported by the project \#RNEp1-18 of the Shun Hing Institute of Advanced Engineering, The Chinese University of Hong Kong, and the National Natural Science Foundation of China (Grant No. 51708474).

\section{References}

1. Wei J, Li Y (2016). Airborne spread of infectious agents in the indoor environment. American Journal of Infection Control, 44: S102-S108.

2. Li X, Niu J, Gao N (2012). Co-occupant's exposure of expiratory droplets-Effects of mouth coverings. HVAC\&R Research, 18: 575-587.

3. Olmedo I, Nielsen PV, Ruiz de Adana M, Jensen RL (2013). The risk of airborne cross-infection in a room with vertical low-velocity ventilation. Indoor Air, 23: 62-73.

4. Chen C, Lin CH, Jiang Z, Chen Q (2014). Simplified models for exhaled airflow from a cough with the mouth covered. Indoor Air, 24: 580-591.

5. Zhang TT, Yin S, Wang S (2011). Quantify impacted scope of human expired air under different head postures and varying exhalation rates. Building and Environment, 46: 1928-1936.

6. Bjørn E, Nielsen PV (2002). Dispersal of exhaled air and personal exposure in displacement ventilated rooms. Indoor Air, 12: 147-164.

7. Qian $\mathrm{H}$, Li Y, Nielsen PV, Hyldgård CE, Wong TW, Chwang AT (2006). Dispersion of exhaled droplet nuclei in a two-bed hospital ward with three different ventilation systems. Indoor Air, 16: 111128.

8. Nielsen PV, Hyldgaard CE, Melikov A, Andersen H, Soennichsen M (2007). Personal exposure between people in a room ventilated by textile terminals - with and without personalized ventilation. HVAC\&R Research, 13: 635-643.

9. Qian H, Li Y, Nielsen PV, Hyldgaard CE (2008). Dispersion of exhalation pollutants in a two-bed hospital ward with a downward ventilation system. Building and Environment, 43: 344-354.

10. Nielsen PV, Li Y, Buus M, Winther FV (2010). Risk of cross-infection in a hospital ward with downward ventilation. Building and Environment, 45: 2008-2014.

11. Olmedo I, Nielsen PV, Ruiz de Adana M, Jensen RL, Grzelecki P (2012). Distribution of exhaled contaminants and personal exposure in a room using three different air distribution strategies. Indoor Air, 22: 64-76.

12. Olmedo I, Nielsen PV, Ruiz de Adana M, Jensen RL (2013). The risk of airborne cross-infection in a room with vertical low-velocity ventilation. Indoor Air, 23: 62-73.

13. Nielsen PV, Zajas J, Litewnicki M, Jensen RL (2014). Breathing and cross-infection risk in the microenvironment around people. ASHRAE Transactions, 120: NY-14-C020, T1-8.

14. Cao G, Nielsen PV, Jensen RL, Heiselberg P, Liu L, Heikkinen J (2015). Protected zone ventilation and reduced personal exposure to airborne crossinfection. Indoor Air, 25: 307-319.

15. Liu L, Li Y, Nielsen PV, Wei J, Jensen RL (2017). Short-range airborne transmission of expiratory droplets between two people. Indoor Air, 27: 452462.

16. Xie X, Li Y, Chwang AT, Ho PL, Seto WH (2007). How far droplets can move in indoor environmentsrevisiting the Wells evaporation-falling curve. Indoor Air, 17: 211-225. 